\title{
EVALUATING THE CAPABILITY OF NEW DISTRIBUTION CENTERS USING SIMULATION TECHNIQUES
}

\author{
Kingkan Puansurin and Jinli Cao \\ Department of Computer Science and Computer Engineering, \\ La Trobe University, Victoria, Australia \\ kinggan@gmail.com and j.cao@latrobe.edu. au
}

\begin{abstract}
One of the difficulties in a product distribution management system of new Distribution Centers(DCs) is no historical data and no experience. In this paper, we develop a product distribution model to estimate the capability of the product distribution system of the new DCs associated a question on the increasing arrival product volumes. In order to develop the model, the exponential distribution and triangular distribution techniques were used to vary on the process of importing arrival product and the operating process in the system. The real life application is used. Chiang Khong, Chiang Sean and Mae Sai DCs in Chiang Rai province, Thailand were applied as the case study. The product distribution system of the new DCs was systematically described by simulating the models. The bottleneck problem finally reflects on the efficiency of the system by improving the capability of the system.
\end{abstract}

\section{KEYWORDS}

Product Distribution Analysis, Product Distribution Model, Modelling Product Distribution Capability System for New Distribution Center

\section{INTRODUCTION}

An increasing demand of product distribution because of rapid economic growth of China is obvious. The southern region of China (Yunnan province) is the majority of agricultural products requires its products transporting to global market. However, its location is in an isolated area surrounding by steep mountains for distributing its products to Chinese seaports. These reasons initiate the North South Economic Corridor (NSEC) originating from the south of China to Thailand via the north of Laos PDR or the north of Myanmar. The NSEC is considered as the best transporting route being a part of the Free Trade Agreement (FTA) of Association of South East Asian Nations (ASEAN) member countries under name of ASEAN-China FTAN or ACFTA [3]. Three new DCs have been establishing in Chiang Rai province, Thailand at Chiang Khong district, Chiang Sean district and Mae Sae district in order to facilitate product distribution originating from Yunnan through the global market.

Natarajan Meghanathan et al. (Eds) : ACSIT, FCST, ITCA, CoNeCo - 2015

pp. 43-59, 2014. @ CS \& IT-CSCP 2015

DOI : $10.5121 /$ csit.2015.51206 
Figure 1 shows the transporting routes from Yunnan pass the northern part of Thailand (Chiang Rai province) to Thai seaport before distributing the products to the global market [6]. The blue line is the waterway transportation that could convey the products from Yunnan to Chiang Rai at Chiang Sean DC. Then these products would be loaded on the trucks at the DCs in order to transport to Thai seaport by using the road network system of Chiang Rai. On the other hand, the gray box on the right side in Figure 1 indeed shows two road transporting routes. The green route is from Yunnan to Mae Sai DC in Chiang Rai province while the red route is from Yunnan to Chiang Khong DC at Chiang Rai province. These road transportation routes would converge in Chiang Rai province and direct the seaport of Thailand via the highway. Consequently, we consider Chiang Khong, Chiang Sean, and Mae Sai DC as the case study in order to simulate the product distribution management system.

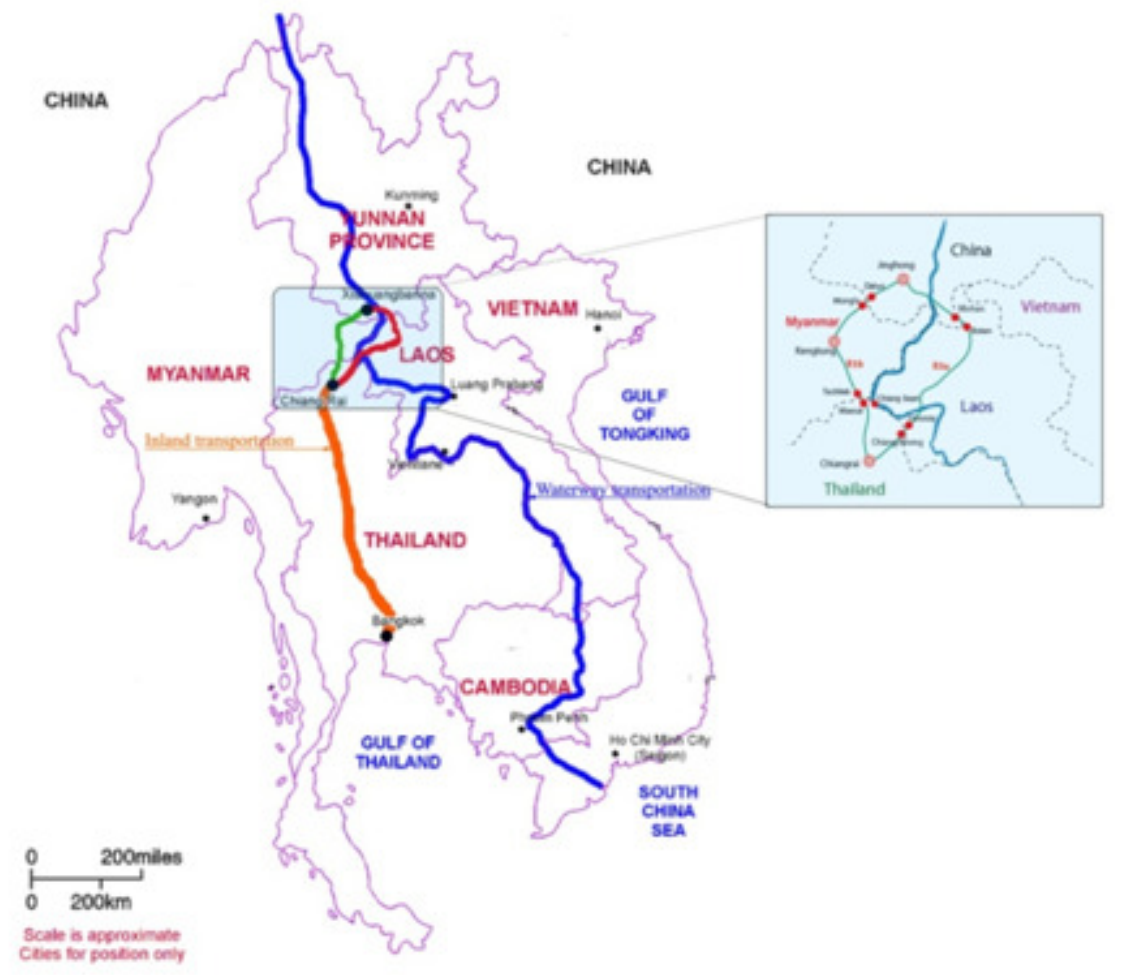

Figure 1. Road and waterway transportation from Yunnan province, China passing three new DCs at Chiang Rai province, Thailand to Thai Seaport

As reviewed literatures, simulation is to design a process model of a real system under the expected conditions, and investigate the model in order to understand the system behaviour or to evaluate various tactics for the system operation before implementing [12], [14]. In addition, ARENA is a commercial software simulating the capability of the model and it is designed for analysing the changing behaviours of the system. Moreover, this software is flexible for simulating various systems such as supply chain, manufacturing, processing, logistics, distribution and warehousing [7], [8]. It was also applied in many field research areas [1], [4], [5], [9], [13].

The comprehensive review of simulation application convinces us to use ARENA to develop the model describing the capability of the system. The scenarios will be proposed to define the unknown amount of the increasing arrival products from the southern part of China. The 
proposed scenarios are expected to identify the possible problem occurring in the system of the new DCs when increasing arrival products as well as improving the efficiency of the system. Finally, we expect that the results of the model could generalise for other similar systems.

\section{RESEARCH OBJECTIVES}

The specific objectives of this paper are: (a) to develop a product distribution model for new DCs in order to systematically describe the capability of the product distribution system, and (b) to reflect the problem of the system in order to apply for improving the capability of the system efficiently.

\section{RESEARCH LIMITATIONS}

The context of this paper considers only the product distribution system established at three new DCs: Chiang Khong, Chiang Sean, and Mae Sai district in Chiang Rai province, Thailand. The operating time of the models is only 12hours a day (06:00 to 18:00). As for period of imported products considering in the study, the data collection was derived in 2012 from the Chiang Khong and Mae Sai model, but Chiang Sean model used the data collection in 2008. The data collection was monthly collected. The monthly maximum arrival product volume will be considered because of the increasing product from Yunnan. Arrival product volumes were assumed to contain in a container.

\section{METHODOLOGY}

This section will provide the fundamental concepts for developing the product distribution model of the new DCs. The model development is based on the field observation and the data collection in order to develop the model as actual as possible. The parameter setting and model are described in order to define the possible problem and to reveal the results.

\subsection{Field Observation and Data Collection}

Due to the study area at three new DCs (Chiang Khong, Chiang Sean and Mae Sai DC in Chiang Rai province, Thailand), the field observation and data collection were done and detailed below.

\subsubsection{Field Observation}

We surveyed the facilities of Chiang Khong, Chiang Sean, and Mae Sai DC. Figure 2 shows the location of Chiang Khong DC using a connection bridge in order to distribute products to Lao PDR. After the arrival products completed all processes at the DC, the finished products will leave the DCs using trucks as shown in Figure 4. Mae Sai DC functions to faciliate the arrival products as same as Chiang Khong DC, but the transporting products are from Myanmar. Figure 3 and 5 show the location of new Chiang Sean DC that functions to facilitate the arrival products transporting by waterway transportation. Then these products will leave the DC by road transportation. 


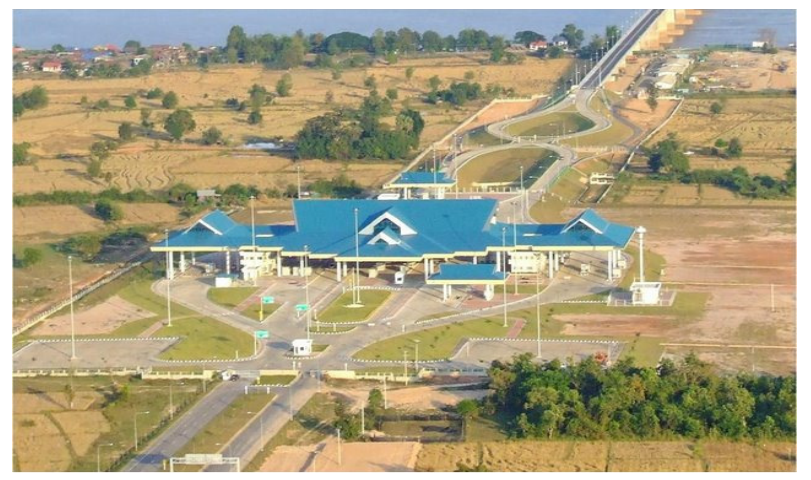

Figure 2. The location of Chiang Khong DC (Source: www.cm108.com)

According to the facilities, all arrival products are contained in containers. Before leaving the DCs, these products will be loaded on the provided trucks. We also notice that the working time of three new DCs is 12 hours per day (06:00-18.00). After the field survey, we could assume the processes of the product distribution system of Chiang Khong and Mae Sai DC. The processes comprise of the custom check service point, storaging the arrival product at the container yard, distributing a container of arrival product by a provided truck.
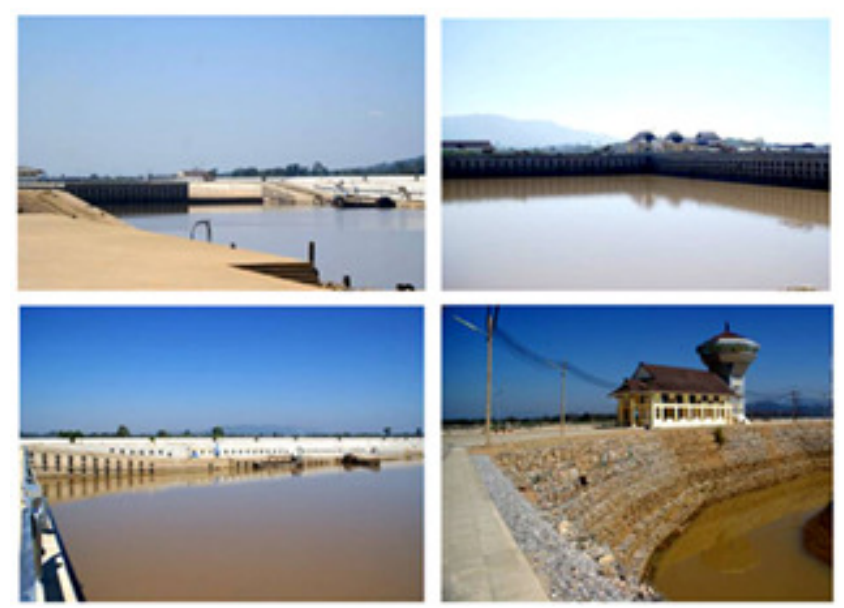

Figure 3. The location of Chiang Sean DC (Source: www.csp.port.co.th)

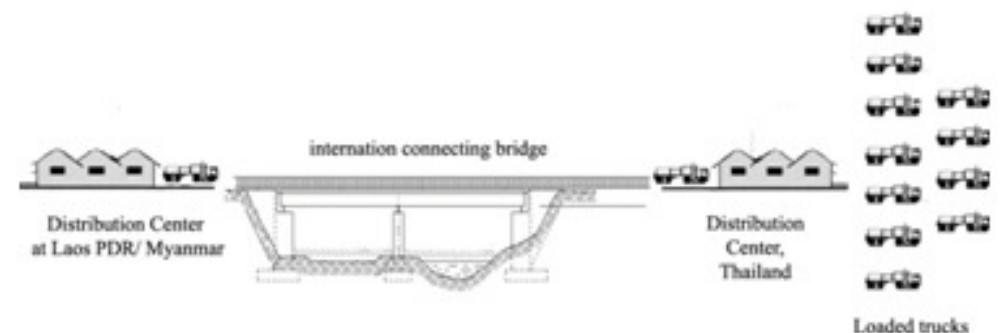

Figure 4. Logic Structure of transporting products from a DC in another country to a DC in Thailand by road transportation 


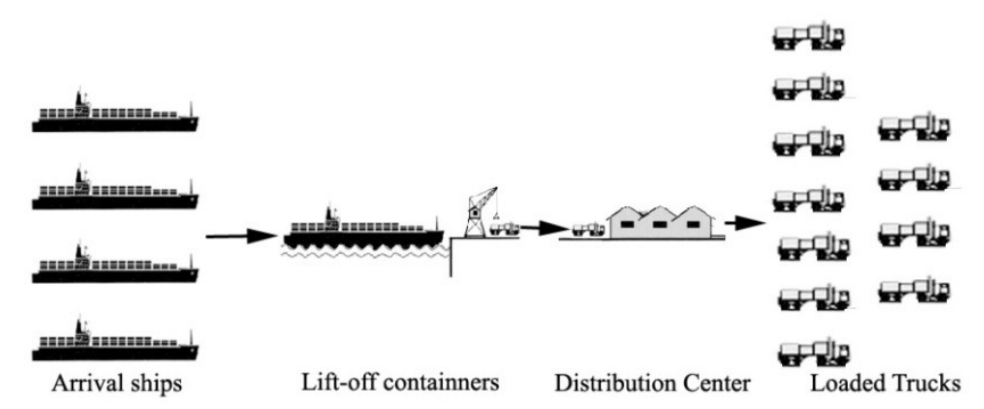

Figure 5. Logic Structure of transporting products from a DC in another country to a DC in Thailand with multiple transportation

The processes of Chiang Sean product distribution system composes of lifting contatiners of arrival products, the custom check service point, distributing a container of arrival product by an available truck.

This survey helps us to design the processess of three new DCs when we develop the product distribution models of three new DCs.

\subsubsection{Data Collection}

We collected the data of arrival products from the southern region of China to Chiang Khong custom house in year 2012, Chiang Sean custom house in year 2009, and Mae Sai custom house in year 2012 as detailed in Table 1. The data collection of the importing product volume of Chiang Khong and Mae Sai custom house was derived from their annually reports [2], [10] while we derived the arrival products of Chiang Sean custom house from the Marine Department, Thailand [11].

We use the collected data as the base of the arrival product volume. However, the derived data is the historical data, but the arrival product volumes expect to increase unknowingly. Before the new DCs will be able to implement, we need to study the capability of the system.

Table 1. Arrival products at Chiang Khong, Chiang Sean, and Mae Sai custom

\begin{tabular}{|l|l|l|l|}
\hline \multirow{2}{*}{ Month } & \multicolumn{2}{|l|}{ Custom } & \multicolumn{2}{|l|}{$\begin{array}{l}\text { Chiang Khong in } \\
\mathbf{2 0 1 2}\end{array}$} & $\begin{array}{l}\text { Chiang Sean } \\
\text { in 2009 }\end{array}$ & $\begin{array}{l}\text { Mae Sai } \\
\text { in 2012 }\end{array}$ \\
\hline January & 25,540 & 18,268 & 11,542 \\
\hline February & 32,280 & 9,467 & 12,688 \\
\hline March & 29,160 & 9,752 & 8,437 \\
\hline April & 26,780 & 9,354 & 12,676 \\
\hline May & 35,020 & 14,407 & 4,941 \\
\hline June & 29,460 & 16,266 & 26,353 \\
\hline July & 39,700 & 29,251 & 5,078 \\
\hline August & 39,080 & 29,223 & 4,103 \\
\hline September & 30,740 & 47,448 & 3,508 \\
\hline October & 34,720 & 51,148 & 5,659 \\
\hline November & 37,560 & 51,001 & 8,783 \\
\hline December & 34,480 & 37,510 & 9,865 \\
\hline Total & 394,520 & 323,095 & 113,633 \\
\hline
\end{tabular}

Unit: Ton 


\subsection{Model Construction}

Based on the field observation and the data collection, two product distribution models were developed. The first model was provided for distributing products by using road transportation, and Chiang Khong, and Mae Sai DCs were applied as the case study (as in Figure 6). Chiang Sean DC was the case study of the product distribution model using waterway transportation and releasing products by road transportation (as in Figure 7). Figure 6 and 7 show the conceptual modules functioning in the product distribution systems with a First-In First-Out (FIFO) queue. An arrival product in the system is contained in a container on a truck. The container will be processed sequentially and immediately if the system is available; otherwise it needs to wait.

The designed model could represent the processes in the system which undergoes with the data requirement to characterize the system. The data requirements for each module in the model will be described in the parameter setting section. Figure 6 explains the process flowchart of the Chiang Khong and Mae Sai DC.

The first component named "Arrival" represents an arrival container that arrives into the system by using the random exponential distribution to simulate the arriving time for a container entering the system.

In the second component, if the "CustomCheck" process is ready to process, the list of invoice of arrival container is needed to be lodged at the Customs service counter. The officer will verify the invoice list and generate the import invoice; otherwise the invoice list will be asked to modify for correction and lodged again. After that, the import invoice needs to be paid.

When completed from "CustomCheck", the payment will be declared with containers of products. Then containers will be stored at the container yard in "LiftAtYard" module in order to wait for available trucks in the next module.

In "LiftOnTruck" module, the payment and containers will be verified and prepared for available trucks. Then containers will be loaded on the available trucks, and continued to leave the system at "Distributing" module in order to transport a container through the road network.

Figure 7 illustrates the process flowchart of Chiang Sean DC where facilitates an arrival container shipped by waterway transportation and it will be flown out off the DC by road transportation. The "Arrival" module in Figure 7 represents a container importing into the system by using the random exponential distribution as same as in Chiang Khong and Mae Sai models. If the system is idle, a container will be lift up from a ship at "LiftUp" module; otherwise it will be hold in a queue. The lift containers will be delivered by the provided facilities in the system. Then, the containers of products need to be declared and moved to the next module after completed.

"CustomCheck" module is the next process that will check a container following the custom regulation as same as in Chiang Khong and Mae Sai systems. After that, a container will be loaded up to an available truck, but there are only $80 \%$ that a container could get an available truck. Then, this truck will transport to the terminal through the road network system [1], [13].

These designed models properly describe and cover the functions of the product distribution system for three new DCs. 


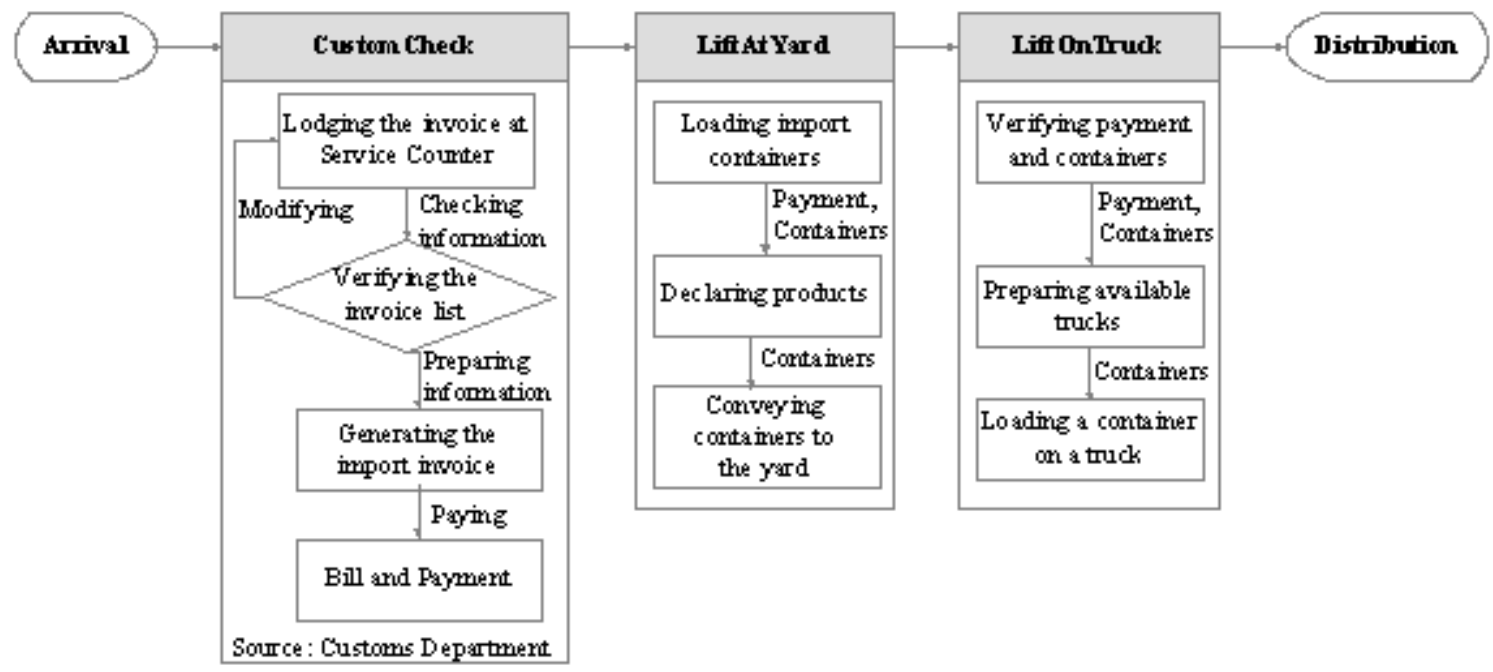

Figure 6. Process flowchart of the product distribution model at the new DC facilitating road transportation

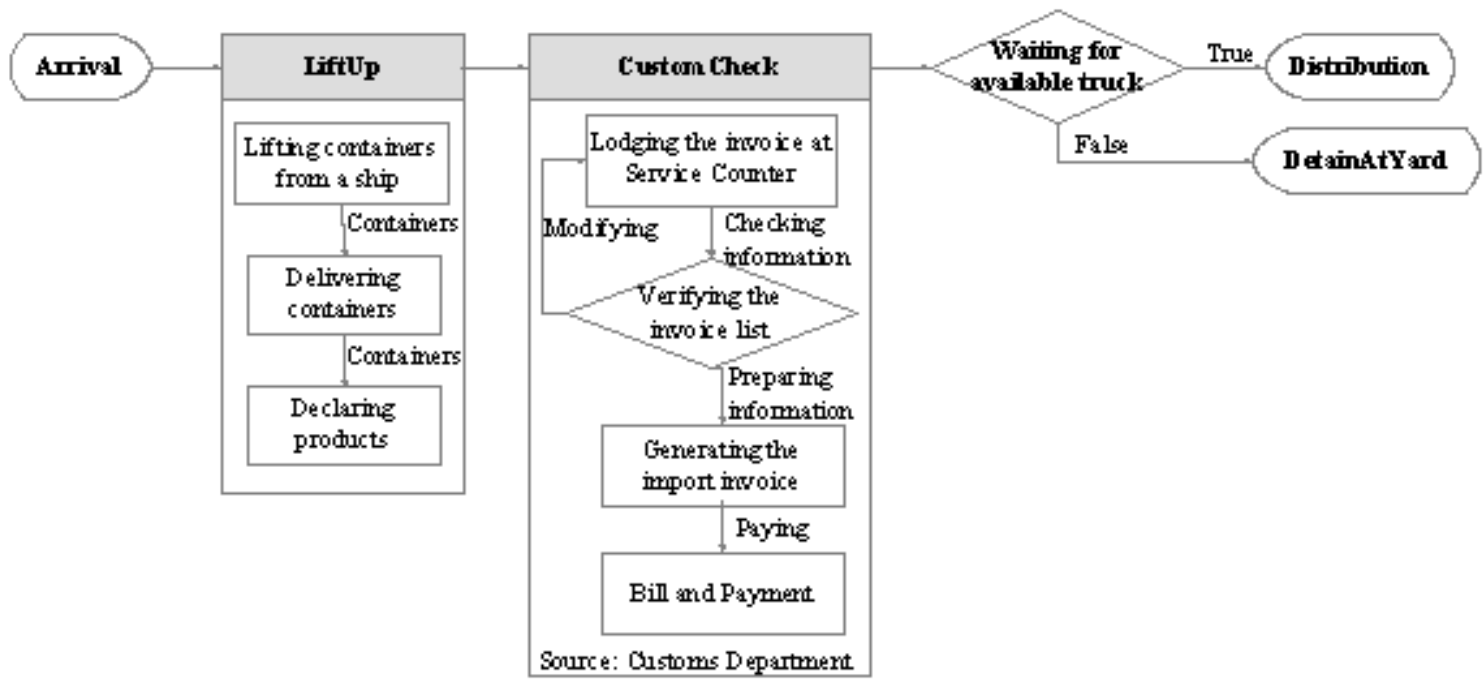

Figure 7. Process flowchart of the product distribution model at the new DC facilitating waterway transportation and releasing as road transportation

\subsection{Parameter Settings}

It is obvious that the volume of importing products from the south of China has dramatically increased, but the unknown volumes of arrival products will be imported to three new DCs. In order to find an appropriated parameter for the system, the various parameters require to examine by the product distribution model. In this work, it is not possible to find the arrival product volumes as well as the capability of the system with the field observation because the facilities of the new DCs are constructing. Therefore, the random exponential distribution and random triangular distribution techniques are used to measure the arrival product volumes and the capability of the system, respectively. 
The random exponential distribution will be used in order to arrange the interval of arrival time for arriving products as same as happening in the real system. The models need to avoided from bias because arrival containers will not enter the system with the specified arriving time. In detail, the following equations will be combined to set the parameters:

$$
x: \Omega \rightarrow S
$$

a random variable $x$ is functioned above by $\Omega$ is the basic simple space; $S$ is named as the state space of $x$ comprising of all possible values that $X$ could attribute. $x$ random number belongs to a standard normal distribution with a standard deviation of one and a zero mean.

$$
F_{x}(x)=1-e^{-\lambda x}, x \geq 0
$$

Exponential distribution: an exponential random variable, $x$, attributes values in the positive halfline $S=[0, \infty]$. The distribution is described by $\operatorname{Expo}(\lambda)$. The $x \sim \operatorname{Expo}(\lambda)$ is by $\lambda$ is called the rate parameter; noted that the corresponding parameter is the mean $1 / \lambda$, in ARENA. Figure 8 shows the probability density function of exponential distribution. The interval (mean) of arriving product will be randomly entered into the system but closed to the interval of arriving product.

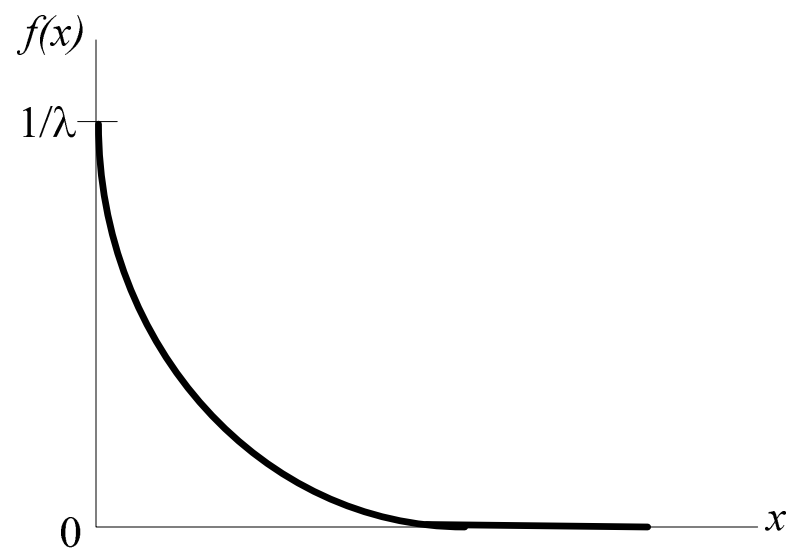

Figure 8 :Probability density function of exponential distribution

$$
f_{x}(x)=\left\{\begin{array}{cc}
\frac{2(x-a)}{(b-a)(c-a),}, & \text { if } a \leq x \leq c \\
\frac{2(b-x)}{(b-a)(b-c)}, & \text { if } c \leq x \leq b \\
0, & \text { otherwise }
\end{array}\right.
$$

Triangular distribution : a triangular random variable $X$ attributes values in an interval $S=[a, b]$, with the "mode" value. The probability linearly goes up in the subinterval $[a, c]$, and linearly goes down in the subinterval $[c, b]$ as shown in Figure 9. The distribution is described by $\operatorname{Tria}(a, b, c)$. 


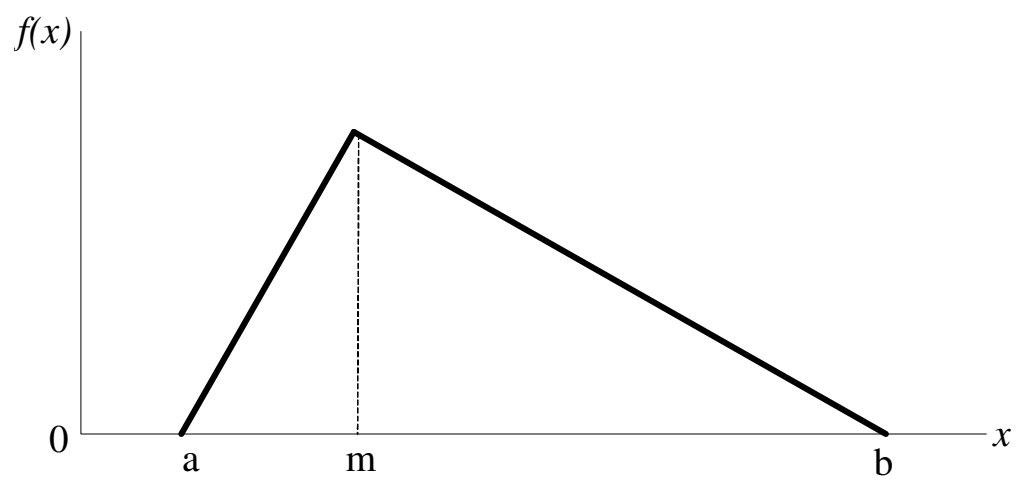

Figure 9 Probability density function of triangular distribution

This technique is simulated for processing in the process module. The behaviours of the process modules compose of the minimum processing time, the delay time (most likely value), and the maximum processing time. Each time in the module will be randomly to specify but closed to the given values.

With the capacity of ARENA, the exponential distribution and the triangular distribution equations are provided as the functions: Random(Expo) and TRAI(minimum, most likely, maximum). The models are assumed to simulate for one working day (12 hours a day). As demonstrated in Figure 6 and 7, we implement these process flowcharts into ARENA. Each component is defined as a module. However, the data requirements for each module in the system are required to be set and stored in a module before running the experiment [7]. Later, the designed model will be simulated to evaluate the capacity of the system.

Table 2. Parameter setting for the product distribution model of the DC facilitating road transportation in ARENA

\begin{tabular}{|c|c|c|}
\hline Module Name & Description & Formula \\
\hline Arrival & Interval arrival time of a container & Random(Expo) \\
\hline CustomCheck & Process time at the custom & TRAI(minimum, most likely, maximum) \\
\hline LiftAtYard & $\begin{array}{l}\text { Process time for lifting a container to } \\
\text { the yard }\end{array}$ & TRAI(minimum, most likely, maximum) \\
\hline LiftOnTruck & $\begin{array}{l}\text { Process time for lifting a container on } \\
\text { a truck }\end{array}$ & TRAI(minimum, most likely, maximum) \\
\hline Distribution & Leave the system & \\
\hline
\end{tabular}

After the models are designed in the software, the parameters of each module will be set as detailed in Table 2. The detail of parameter setting in Table 2. is used for the model of Chiang Khong and Mae Sai because the model designed for road transportation.

This is the example for parameter settings of Chiang Khong model. The system will set 12 hours for one working day because the working hours per day of Chiang Khong are 12 hours (06:0018:00).

In "Arrival" module, we define to use Random(Expo) formulation so that the interval times of an arrival container will be randomly generated following the exponential distribution equation. As we based on the data collection (detailed in Table 1.), the highest volume of the arrival products 
in 2012 at Chiang Khong custom house was 39,700 tons in July. We divide 39,700tons by 20 in order to convert a weight of ton into a container because we assume to transport an arrival product container by a truck (one container loading on one truck). There are 66 containers importing into the model in 12 hours. It means 66 containers will continue importing into the model one by one to process in every 11 minutes. Therefore, we set the value for Random(Expo) formulation equals 11 .

For "CustomCheck", "LiftAtYard", and "LiftOnTruck" modules, we set the action for these modules as "Seize Delay Release". This action identifies the system would seize the resource of the system for processing a module when processing an arrival container. The action will be automatically set as delay action when the module is processing. The waiting containers will wait in a queue to be processed. These containers will use FIFO rule when the module is idle to process. "CustomCheck", "LiftAtYard", and "LiftOnTruck" modules will use TRAI(minimum, most likely, maximum) as Triangular probability distribution formulation. This formulation indicates the probability distribution of an arrival container spending time in a module. Triangular probability composes of the minimum, most likely and maximum time values that are required to be set in Triangular probability distribution formula. "CustomCheck" module will be set $\operatorname{TRAI}(15,20,25)$ because the custom normally consumes 15 minutes to complete the work in a module, 20 minutes for the time of delay in a process, and 25 minutes in the maximum duration of a process. "LiftAtYard" and "LiftOnTruck" modules will be set TRAI $(8,12,16)$ because the work will be done in these modules using for 8 minutes. The time delay in these modules is 12 minutes while the maximum processing time is 16 minutes.

Mae Sai product distribution model is similar to Chiang Khong model. Some values need to adjust due to the arrival products at Mae Sai custom in 2012 and its facilities. The value of Random(Expo) formulation at "Arrival" module equals 16 because the highest volume of the arrival product at Mae Sai was 44 containers per day in June 2009. "CustomCheck" module will be set the value for the function as same as the CustomCheck" module of Chiang Khong because the custom check procedures have done similarly. "LiftAtYard" and "LiftOnTruck" modules will be set TRAI $(8,10,12)$ because Mae Sai DC can facilitate faster than Chiang Khong DC. Mae Sai DC has smaller size than Chiang Khong DC but its arrival product volumes were less than Chiang Khong.

On the other hand, the modules of Chiang Sean model compose of "Arrival", "LiftUp", and "CustomCheck" components as shown in Table 3. In "Arrival" module, the value for Random(Expo) sets to 8. The data collection of Chiang Sean custom house in 2009 will be calculated as same as done in Chiang Khong and Mae Sai models. The value for TRAI(minimum, most likely, maximum) in the "LiftUp" module sets to TRAI $(15,20,25)$ because of the field survey. For "CustomCheck" module, the value will be set as same as the "CustomCheck" module of Chiang Khong and Mae Sai models. Since arrival containers ship by waterway transportation and change to road transportation, these containers need to put in a decision module. In the real system, a provided truck may not be available for distributing a container when it is completed. In "Decide" module, we will set $80 \%$ for the probability of delivery by an available truck, and $20 \%$ for the probability of detention when there is no available truck [8]. However, the parameter setting is an example for the model. The modellers are allowed to readjust and organise the model as appropriated. 
Table 3. Parameter setting for the product distribution model at the new DC facilitating waterway transportation and releasing as road transportation in ARENA

\begin{tabular}{|l|l|l|}
\hline Module Name & Description & Formula \\
\hline Arrival & Interval arrival time of a container & Random(Expo) \\
\hline LiftUp & $\begin{array}{c}\text { Process time for lifting up a container } \\
\text { from a ship }\end{array}$ & TRAI(minimum, most likely, maximum) \\
\hline CustomCheck & Process time at the custom & TRAI(minimum, most likely, maximum) \\
\hline Decide & $\begin{array}{c}\text { Consideration for delivery or } \\
\text { detention }\end{array}$ & $\begin{array}{c}80 \% \text { for delivering a container (True) 20\% } \\
\text { for detaining a container (False) }\end{array}$ \\
\hline Distribution & Leave the system & \\
\hline
\end{tabular}

\subsection{Model Application}

In our study, we formulated the model to explain the capacity of the system. As mentioned, the arrival product volumes from the south of China has dramatically increased, but the arrival product volumes that importing into three new DCs are unknown. We collected the data of the arrival product volumes in Chiang Khong, Chiang Sean, Mae Sai custom house in 2012, 2009, and 2012, respectively. We used these data as the base for modelling.

We propose a scenario for model application in order to estimate the arrival product volumes importing to the new DCs systematically. We assume that arrival product volume would increase from the base data to $25 \%, 50 \%, 75 \%$, and $100 \%$, respectively. This is because we expect that the experiment can describe the capacity of the systems. We also expect that the capability of all processes will be revealed. Therefore, we can offer the solutions or the alternatives for the system in order to prevent the and the models can be generalise in similar systems.

\section{COMPUTATIONAL RESUltS}

After developing the models and setting the parameters, we will experiment the model considering the proposed scenario. We expect to evaluate the capacity of the product distribution system by increasing the unknown arrival products. Our scenario is to increase the unknown arrival products from the base data to $25 \%, 50 \%, 75 \%$, and $100 \%$. As mentioned, the working time of the system for one day is 12 hours (06:00-18:00).

Table 4. shows the result of Chiang Khong model. The waiting number of trucks per 12 working hours in "CustomCheck", "LiftAtYard", and "LiftOnTruck" process is detailed. Table 4. also reports the number out from the system, and total number of arrival truck.

The total number of arrival truck in the system relates to our criteria $(25 \%, 50 \%, 75 \%$, and $100 \%$, respectively). However, the number out from the system (truck/12hr) in all criteria slightly increases. It is interesting that many arrival trucks are waiting for "CustomCheck" process when comparing with "LiftAtYard" and "LiftOnTruck" process.

Under the same conditions of Chiang Khong model, Table 5. shows the result of Chiang Sean model. It also reports the waiting number of trucks per 12working hours in "LiftUp" and "CustomCheck" process. The transporting trucks from the system, and total number of arrival truck are detailed. We notice that Chiang Sean model confront the same problem of Chiang 
Khong model. The first module ("LiftUp") has a long queue waiting for processing. The increase of the waiting number in this module relates to the criteria of increasing arrival truck.

Table 4. Result from Chiang Khong model by increasing arrival trucks

\begin{tabular}{|c|c|c|c|c|c|}
\hline \multirow{2}{*}{$\begin{array}{l}\text { Increasing } \\
\text { arrival } \\
\text { truck }\end{array}$} & \multicolumn{3}{|c|}{ Waiting number in a module (truck/12hr) } & \multirow[b]{2}{*}{$\begin{array}{l}\begin{array}{c}\text { Number out } \\
\text { from the }\end{array} \\
\text { system } \\
\text { (truck/12h } \\
\text { r) }\end{array}$} & \multirow[b]{2}{*}{$\begin{array}{l}\text { Total number } \\
\text { of arrival } \\
\text { truck } \\
\text { (truck/12hr) }\end{array}$} \\
\hline & CustomCheck & LiftAtYard & LiftOnTruck & & \\
\hline Base data & 7 & 7 & 1 & 52 & 67 \\
\hline$+25 \%$ & 12 & 11 & 2 & 54 & 79 \\
\hline$+50 \%$ & 28 & 12 & 3 & 56 & 99 \\
\hline$+75 \%$ & 30 & 14 & 2 & 56 & 102 \\
\hline$+100 \%$ & 53 & 12 & 1 & 57 & 123 \\
\hline
\end{tabular}

Table 5. Result from Chiang Sean model by increasing arrival trucks

\begin{tabular}{|l|l|l|l|l|}
\hline \multirow{2}{*}{$\begin{array}{c}\text { Increasing arrival } \\
\text { truck }\end{array}$} & $\begin{array}{l}\text { Waiting number in a module } \\
\text { (truck/12hr) }\end{array}$ & $\begin{array}{l}\text { Number out } \\
\text { from } \\
\text { system } \\
\text { (truck/12hr) }\end{array}$ & $\begin{array}{l}\text { Total number of } \\
\text { arrival truck } \\
\text { (truck/12hr) }\end{array}$ \\
\cline { 2 - 4 } & LiftUp & CustomCheck & 61 \\
\hline Base data & 27 & 1 & 33 & 69 \\
\hline$+25 \%$ & 34 & 1 & 33 & 74 \\
\hline$+50 \%$ & 40 & 1 & 33 & 86 \\
\hline$+75 \%$ & 52 & 1 & 33 & 105 \\
\hline$+100 \%$ & 70 & 1 & 34 & \\
\hline
\end{tabular}

Table 6. reports the waiting number is each module of Mae Sai product distribution system, the number of trucks out from the system, and the total number of arrival trucks in the system. With the same conditions such as working hours per day, and criteria of increasing arrival products, the number of trucks out from the system continuingly increases. The waiting number of truck in each module is not significant.

Table 6. Result from Mae Sai model by increasing arrival trucks

\begin{tabular}{|c|c|c|c|c|c|}
\hline \multirow{2}{*}{$\begin{array}{c}\text { Increasing } \\
\text { arrival } \\
\text { truck }\end{array}$} & \multicolumn{3}{|c|}{ Waiting number in a module (truck/12hr) } & \multirow{2}{*}{ 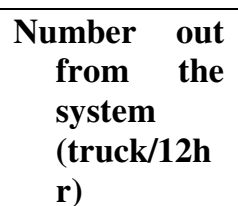 } & \multirow{2}{*}{$\begin{array}{c}\text { Total number } \\
\text { of arrival } \\
\text { truck } \\
\text { (truck/12hr) }\end{array}$} \\
\hline & CustomCheck & LiftAtYard & LiftOnTruck & & \\
\hline Base data & 3 & 1 & 1 & 38 & 43 \\
\hline$+25 \%$ & 5 & 1 & 1 & 59 & 66 \\
\hline$+50 \%$ & 6 & 2 & 1 & 61 & 70 \\
\hline$+75 \%$ & 8 & 2 & 1 & 61 & 72 \\
\hline$+100 \%$ & 15 & 2 & 1 & 66 & 84 \\
\hline
\end{tabular}

In addition, the waiting number in each module of Chiang Sean is very high. The system and Chiang Khong model also confront the same problem, but not serious as in Chiang Sean system. Mae Sai system can manage the system well with few waiting numbers of truck in each module. 


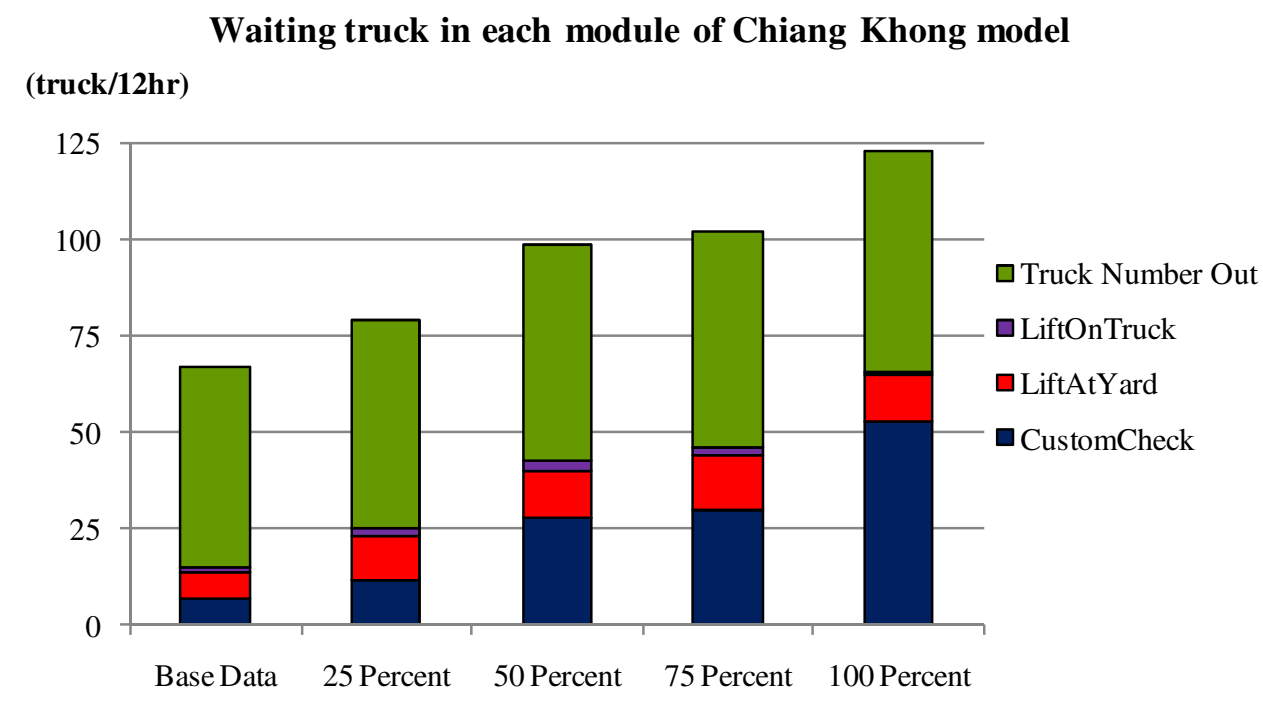

Figure 10. Waiting truck in each module of Chiang Khong model

Figure 10. illustrates that Chiang Khong system faced with the bottleneck problem. The problem shows with the number of waiting trucks per 12 hours in each module of the system. With the criteria of increasing arrival trucks into the system from the base data to $25 \%, 50 \%, 75 \%$, and $100 \%$, the total number of trucks in the system relates to the proposed criteria. The waiting truck number is particularly significant in the first module ("CustomCheck"). The waiting trucks in the second module ("LiftAtYard") are small while there is very few in the third module ("LiftOnTruck"). The bottleneck problem is the issue on the first process because the volume of arrival trucks, and the processing time were higher than others. However, the capability of the system can maintain its system well because the ratio of trucks out from the system and waiting trucks in modules are 2 to 1 . The ratio slightly declines when increasing the arrival trucks following the conditions. It is because the capability of the system becomes overloaded.

The results from the experiment indicate Chiang Sean system confronts the serious bottleneck problem more than other systems because the arrival products imported to the system were higher than others almost $30 \%$ as referred in the data collection. Figure 11. shows the number of trucks waited for processing in each module in one working day (12hours). In two modules of Chiang Sean system, there is a long queue in the first module named "LiftUp" module, but it is not significant in the second module ("CustomCheck"). Indeed, the number of waiting truck for processing increasingly related with the criteria of increasing arrival from the base data to $25 \%$, $50 \%, 75 \%$, and $100 \%$. The total number of waiting truck in 12 hours of Chiang Sean system is almost 75 trucks per 12 hours at increasing arrival product for $100 \%$. When comparing with the finished trucks from the system, the ratio of the waiting trucks and the finished trucks in the system is 3 to 1 .

However, the waiting truck was very few in the second module because all modules of the system was processed sequentially. All arrival trucks were required to complete the process at the first module. All trucks waited for processing in a queue at the first module as well, so the second module could have time to finish its process while the waiting truck for processing in module was usually less than the first module. Therefore, the bottleneck problem is very serious for Chiang 
Sean system because it indicates that the capability of the system cannot maintain its system to release the trucks out of the system. Specifically, LiftUp module is the weakest point for the system, so this module should be urgently fixed.

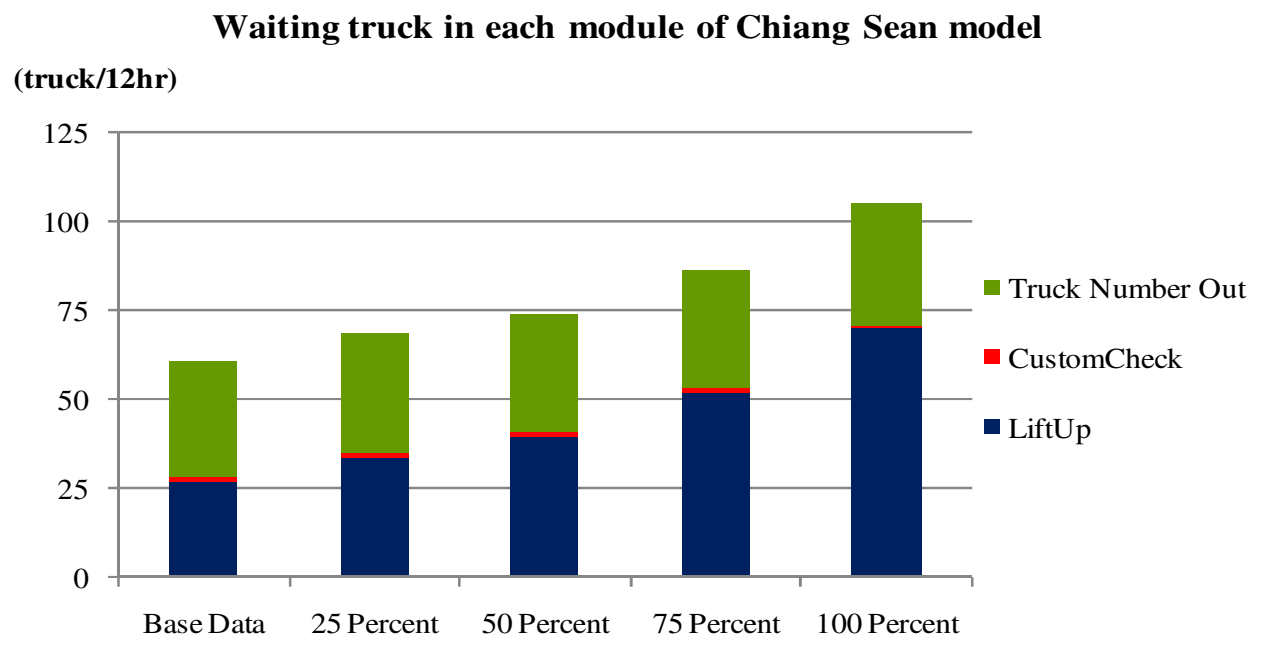

Figure 11. Waiting truck in each module of Chiang Sean model

On the contrary, Mae Sai system shows that it can manage its system very well as described in Figure 12. The bottleneck problem is not a problem for Mae Sai system because there is very few waiting trucks per 12 hours in each module. Although the trucks out from the system are less than other systems, the finished trucks out from the system following the criteria $25 \%, 50 \%, 75 \%$, and $100 \%$ are relatively significant. Therefore, the capability of the system can handle with $100 \%$ increasing arrival trucks. It would be better for Mae Sai system to increase more importing trucks into the system for $150 \%$ or $200 \%$.

Waiting truck in each module of Mae Sai model

\section{(truck/12hr)}

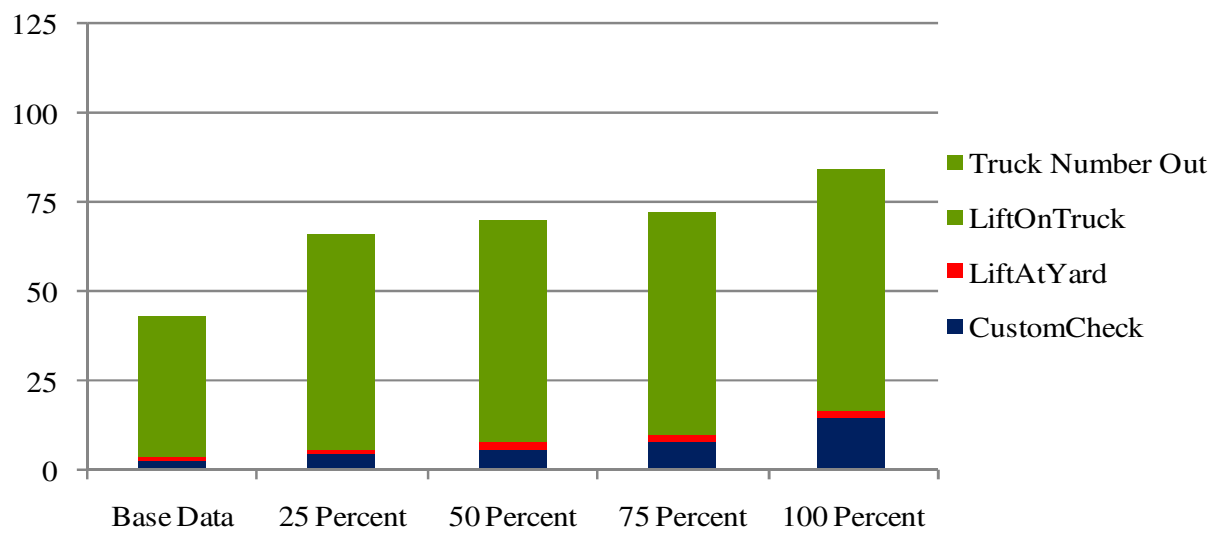

Figure 12. Waiting truck in each module of Mae Sai model 


\section{CONCLUSION AND DISCUSSION}

Regarding to the objectives of our research, we propose to develop a model of product distribution system for new DCs in order to evaluate the capability of the system, and we expect that the designed model can reflect the problem of the system that can efficiently use to improve the capability of the system. The system of Chiang Khong, Chiang Sean, and Mae Sai DC were the study area of this paper. These three DCs have been under constructing for facilitating the increasing arrival products from the southern part of China. It becomes difficult because there is no recorded data and no experience at these new DCs. Therefore, the increasing arrival products that will be imported into these new DCs are unknown.

To model the product distribution system for these new DCs, we used the efficiency of ARENA to develop the model relating to the field survey of facilities, and the data collection of the arrival products from the past year. Chiang Khong and Mae Sai models had the same processes that comprised of "Arrival", "LiftAtYard", "LiftOnTruck" modules. Chiang Sean model was designed to import the arrival product from ship and distributed the completed products by truck. The modules of Chiang Sean system composed of "LiftUp" and "CustomCheck" processes.

During the model development, the parameters in each process of the designed systems needed to be set. The random exponential distribution and the random triangular distribution techniques were used. The exponential distribution technique was used for importing the arrival product into the system. This technique could simulate as same as the actual system. Each arrival product containing in a container was randomly generated into the system in every specific time. Only one container could be processed in a module and it would sequentially continue to the next module when it was done. For another technique, it was used for the process module because the triangular distribution functions for three circumstances that are the completed work, the delay time waiting for processing, and the maximum time for processing.

Due to the unknown arrival product transporting to the new DCs, we proposed the scenario to evaluate the capability of the models by increasing the arrival product from the base data to $25 \%$, $50 \%, 75 \%$ and $100 \%$. After the experiment, the result showed that the product distribution system of Mae Sai DC operated well. Almost $100 \%$ of arrival trucks can finish and leave all processes with very few waiting trucks in the system. The system of Chiang Khong and Chiang Sean reflect the bottleneck problem especially its first process. The first process of these two models has a long queue waiting for processing. We found that the capability of the first process of Chiang Khong and Chiang Sean models could not handle with the condition of increasing arrival trucks. Chiang Khong system deals with the bottleneck problem better than Chiang Sean system, because Chiang Khong system can release the finished trucks out from its system more than 50\% of arrival trucks. Moreover, the queue of Chiang Khong model in the first process was less than the queue of Chiang Sean model in the first process because the arrival product volumes of Chiang Khong model were less than the arrival products of Chiang Sean model.

In conclusion, the designed models for the new DCs successfully developed. The results from the experiment reflect the capability of the systems. We suggest that these three new DCs should double the capability of each module because the bottleneck problem occurred in the system. After doubling the capability of each module, we also recommend to increase the criteria of increasing arrival product volume to $150 \%$ and $200 \%$, so we can expand our view and we may 
handle the wider problem. Finally, we notice that ARENA is capable of problem identification for the system, so the developed models can be generalised for similar systems.

\section{ACKNOWLEDGEMENTS}

The work described in this paper was sponsored by Rajamangala University of Technology Lanna (RMUTL), Thailand.

\section{REFERENCES}

[1] Cheng, Lifei. \& Duran, Marco A., (2002) "World-Wide Crude Transportation Logisitics: A Decision Support System Base on Simulation and Optimization", In Proceedings Foundations of Computer Aided Process Operations, pp187-201.

[2] Chiang Khong Customs House, (2012) Operational Annual Report 2008-2012, Chiang Rai, Thailand.

[3] Cordenillo, Raul L., (2005) The Economic Benefits to ASEAN of the ASEAN-China Free Trade Area (ACFTA), http://www.asean.org.

[4] Das, Shantanu, \& Levinson, David, (2004) "Queuing and Statistical Analysis of Freeway Bottleneck Formation", Journal of Transportation Engineering ASCE, pp787-795.

[5] Fahimnia, Behnam, Luong, Lee. \& Marian, Romeo, (2008) "Optimization/simulation modelling of the integrated production distribution plan: an innovative survey", WSEAS Transactions on Business and Economics, Vol.5, No.3, pp52-65.

[6] Kasikorn Research Center, Mega Projects of Transportation: Move forward even increasing cost, http://www.kasikornresearch.com.

[7] Kelton, W.David, Sadowski, Randall P. \& Sadowski, Deborah A., (1998) Simulation with Arena, McGraw Hill, McGraw Hill Publishing.

[8] Kelton, W.David, Sadowski, Randall P. \& Sturrock, David T., (2003) Simulation with Arena, (3eds), McGraw Hill, McGraw Hill Publishing.

[9] Kleinschmidt, Tristan, Guo, Xufeng, Ma, Wenbo, Yarlagadda, Prasad K.D.V., (2011) "Including Airport Duty-Free Shopping in Arrival Passenger Simulation and the Opportunities this Presents", In Proceedings of the 2011 Winter Simulation Conference.

[10] Mae Sai Customs House, (2012) Operational Annual Report 2008-2012, Chiang Rai, Thailand

[11] Marine Department of Thailand. http:// www.md.go.th/md/

[12] Shannon, Robert E., (1975) Systems Simulation: The Art and Science, Prentice-Hall, Englewood Cliffs.

[13] Teri, Sergio. \& Cavalieri, Sergio, (2004) "Simulation in the supply chain context: a survey", Computers in Industry Transactions on ScienceDirect, Vol.53, No.1 pp3-16.

[14] Vieira, Guilherme Ernani, (2004) "Ideas for Modelling and Simulation of Supply Chains with ARENA", In Proceedings of the 2004 Winter Simulation Conference, Vol. 2, pp1418-1427.

\section{AUTHORS}

Kingkan Puansurin is currently a $\mathrm{PhD}$ (Computer Science) student at La Trobe University. Her research is mainly concerned with methods and techniques for Multiple Criteria Decision Analysis and Modelling.

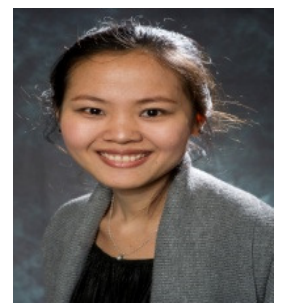


Jinli Cao Dr Cao is a Senior Lecturer in Department of Computer Science and IT, La Trobe University, Melbourne Australia. She has been active in areas of database systems, Key words search in XML documents, Top-K query on probabilistic data and Web Services. She ha $\mathrm{s}$ published over 80 research papers in refereed international journals and conference proceedings such as IEEE Transactions on Distributed and Parallel Processing, IEEE Transactions on Knowledge and Data Engineering (TKDE) etc.

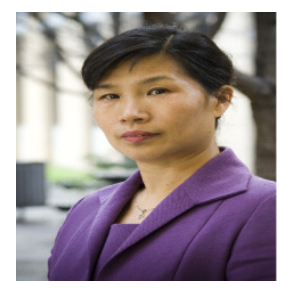

